УДК 373.1

\title{
ПРОЕКТИРОВАНИЕ МОДЕЛИ СОВРЕМЕННОГО ЧЕЛОВЕКА В ОБРАЗОВАТЕЛЬНОЙ СИСТЕМЕ ШКОЛЫ
}

\author{
Ломова Дарья Антоновна \\ магистрант направления подготовки \\ «Педагогическое образование» \\ профиль «Иностранный язык» \\ МГУТУ имени К.Г. Разумовского (ПКУ) \\ Научный руководитель: Рабаданова Разият Сулайбановна \\ к.пед.н., доцент
}

Аннотация: Предпосылки исследования: Актуальность проектирования новой модели человека в образовательной системе, особенно в старшей школе, обусловлена необходимостью пересмотра содержания образования и принципов организации учебно-воспитательного процесса в силу изменения внешней социальной и образовательной ситуации. Многие годы традиционной целью школьного образования было овладение системой знаний, составляющих основу наук. Но современные условия диктуют необходимость пересмотра традиционных образовательных моделей. Актуальной педагогической проблемой является неподготовленность выпускников к самостоятельной жизни и работе. Также на сегодняшний день не определены основополагающие идеи создания модели выпускника современной школы, необходимые для определения основных личностных качеств, которыми должен обладать выпускник XXI века.

Ключевые слова: модель человека, проектирование модели человека, образовательная система современной школы.

\section{DESIGNING A MODEL OF A MODERN PERSON IN THE SCHOOL'S EDUCATIONAL SYSTEM}

\section{Lomova Darya Antonovna} Scientific adviser: Rabadanova Raziyat Sulaybanovna

\footnotetext{
Abstract: Background of the study: The relevance of designing a new human model in the educational system, especially in high school, is due to the need to
} 
revise the content of education and the principles of the organization of the educational process due to changes in the external social and educational situation. For many years, the traditional goal of school education was to master the system of knowledge that forms the basis of sciences. But modern conditions dictate the need to revise traditional educational models. The actual pedagogical problem is the unpreparedness of graduates for independent life and work. Also, to date, the fundamental ideas of creating a model of a graduate of a modern school have not been defined, which are necessary to determine the basic personal qualities that a graduate of the XXI century should possess.

Keywords: human model, human model design, educational system of a modern school.

Введение. В педагогической науке проблема определения человеческой сущности, создания идеального образа человека выражается в изменении имеющихся идеалов личности и моделировании новых. Модели служат условными ориентирами образовательной деятельности, помогают конкретизировать ее направления.

Методологические основы работь. Современные условия информационного общества влияют на развитие образовательной системы, поэтому сегодня уже сложно говорить о какой-либо конкретной модели человека как ориентире для образовательной модели личности. Кроме того, растущая «пропасть» между гуманитарным и негуманитарным знанием, между разными видами специализированного образования рассматривается как опасная и сама по себе губительная тенденция современной культуры, современного общества (Ю.Н. Афанасьев, А.С. Запесоцкий, И.В. Кучер и др.). Как способы решения этих проблем на первое место выдвигаются задачи гуманизации образования, реализации в нем культурологического, антропоцентрического, личностно-ориентированного подходов.

Сегодня речь идет о новом человеке, который начинает по-новому осознавать ответственность за свои действия. В современной культуре выдвигаются принципиально иные требования к человеку, его становлению. И важную роль здесь играет образование, которое в своих формирующих моделях личности должно быть ориентировано на самые сущностные свойства человека. К таким свойствам исследователи, например, относят способность 
сознавать мир в духовных категориях, способность к самосовершенствованию. Сегодня важно воспитать активную личность, способную к решению стоящих перед ней индивидуальных и социальных проблем, готовую к сотрудничеству и конструктивному диалогу.

H.M. Сурнина считает, что в рамках образовательной системы необходимо сформировать у учащихся способность жить в цифровом мире и не потерять человечность. Учеников нужно научить верифицировать, проверять, распознавать информацию, противостоять стрессу, воспитать способность к переменам, научить постоянно учиться. Поэтому образование будущего - это образование понимания, а не запоминания [3, с. 88].

Целью данного исследования является определение основных элементов модели человека в проектировании образовательной системы среднего общего образования.

Задачи исследования:

1) проанализировать теоретические подходы к пониманию структурных элементов модели человека в проектировании образовательной системы;

2) выделить ключевые качества современного учащегося школы;

3) сопоставить полученные данные с программами развития современных школ.

Memodbl. Для достижения поставленной цели и решения задач использовались такие методы исследования как анализ теоретических источников и литературы, анализ документов, синтез, сравнение, анализ опыта, обобщение, моделирование.

Результаты исследования. Обобщение имеющихся теоретических данных позволило сформировать авторский взгляд на проблему модели личности в современной образовательной системе. За основу структурных элементов проектируемой модели личности обучающегося мы взяли подходы, используемые к проектированию образовательной системы: условия функционирования, личностные характеристики, компетенции. Их содержание приведено в таблице 1. 
Таблица 1

\section{Модель формируемой личности}

в современной образовательной системе школы

\begin{tabular}{|l|l|}
\hline $\begin{array}{l}\text { Элементы модели } \\
\text { человека }\end{array}$ & \multicolumn{1}{c|}{ Содержание } \\
\hline Подходы & $\begin{array}{l}\text { культурологический, антропоцентрический, личностно- } \\
\text { ориентированный }\end{array}$ \\
\hline Условия & информационное общество, цифровое общество \\
\hline $\begin{array}{l}\text { Личностные } \\
\text { характеристики }\end{array}$ & $\begin{array}{l}\text { способность к самосовершенствованию, активность, } \\
\text { стремление к сотрудничеству, способность к переменам }\end{array}$ \\
\hline Компетенции & $\begin{array}{l}\text { способность самостоятельно добывать знания, } \\
\text { способность эффективно работать, способность } \\
\text { полноценно жить в обществе, коммуникативные навыки }\end{array}$ \\
\hline
\end{tabular}

Обсуждение результатов. Многие современные школы опираются в построении модели ученика на ФГОСы. В частности, ФГОС среднего общего образования предлагает включить в портрет выпускника школы следующие характеристики: любовь к Родине, принятие традиционных ценностей семьи и общества, креативность, критическое мышление, мотивация на образование и самообразование в течение всей своей жизни, готовность к учебному сотрудничеству, осознание себя личностью, социальная активность, умение взаимодействовать с людьми, ведение здорового образа жизни, подготовленность к осознанному выбору профессии [4], [5], [6].

Многие из этих основополагающих характеристик личности отражены в программах развития современных школ. Так, например, Программа развития Богородской школа г. Москвы № 1797 на период 2020-2025 гг. «От успеха в школе к успеху в жизни» содержит «Модель выпускника-2025». Данная модель строится на основе национального образовательного идеала высоконравственный, творческий, компетентный гражданин России, принимающий судьбу Отечества как свою личную, осознающий ответственность за настоящее и будущее своей страны, укорененный в духовных и культурных традициях российского народа.

Результатом деятельности школы станут, с одной стороны, сформированные личностные качества выпускника, а с другой стороны, компетенции выпускника, значимые в социальном окружении и компетентности.

Модельные потребности выпускника - это стремление к позитивной самореализации себя в современном мире. 
Модельные компетенции выпускника - это прочные знания по школьным предметам обучения.

Модельные компетентности выпускника - это способность самостоятельно добывать знания, способность эффективно работать, способность полноценно жить в обществе [2].

Модель выпускника школы №2001 г. Москвы включает в себя следующие составляющие: знание своего культурного наследия, способность понимать и ценить другие культуры, забота о своем здоровье и здоровье окружающих, умение ставить перед собой личные цели, организовывать свою деятельность, строить планы, правовая грамотность, желание самореализовываться и трудиться на благо Родины, способностью понимать научные концепции, принципы работы компьютеров, навыки в работе с информационной техникой, культура общения в коллективе, умение находить, обобщать, исследовать и анализировать нужную информацию и различные данные, опираясь на полученные ранее знания и опыт, сформированность нравственных норм поведения, сочувствия и сопереживания другим людям [1], $[5],[6]$.

Заключение. Таким образом можно сделать вывод, что проектирование модели человека в современной образовательной системы среднего общего образования должно опираться на потребности современного общества, учитывать постоянные изменения среды, в которой живут и взаимодействуют люди. Также необходимо учитывать условия, в которых будет жить, учиться и работать человек. При этом качество знаний должно соответствовать требованиям времени.

\section{Список литературы}

1. ГБОУ г. Москвы «Школа № 2001» [Электронный ресурс]. - URL: http://www.sch2001.ru/index.php?sid=1344 (дата обращения: 14.12.2021).

2. Программа развития ГБОУ г. Москвы № 1797 «Богородская» на 2020-2025 гг. [Электронный pecypc]. - URL: https://gym1797.mskobr.ru/attach_files/upload_users_files/5f99421eb53ec.pdf (дата обращения: 14.12.2021).

3. Сурнина, Н. М. Человек в информационную эпоху: культурная или цивилизационная модель развития и образования / Н. М. Сурнина // Осознание Культуры - залог обновления общества. Перспективы развития современного общества: мат. XXI Всерос. науч.-практ. конф. - 2020. - С. 87-90. 
4. ФГОС Среднее общее образование. Приказ Минобрнауки России от 17.05.2012 № 413 [Электронный pecypc]. - URL: https://fgos.ru/fgos/fgos-soo/ (дата обращения: 14.12.2021).

5. ПСИХОЛОГО-ПЕДАГОГИЧЕСКОЕ

СОПРОВОЖДЕНИЕ ВОСПИТАНИЯ ЛИЧНОСТИ В ИНФОРМАЦИОННУЮ ЭПОХУ/Сборник материалов международной научно-практической конференции / 2020.

6. Шишов С. Е., Рабаданова Р. С. РЕАЛИЗАЦИЯ ЛИЧНОСТНОДЕЯТЕЛЬНОСТНОЙ КОНЦЕПЦИИ ПРИ ФОРМИРОВАНИИ ОБЩЕКУЛЬТУРНЫХ КОМПЕТЕНЦИЙ В ТЕХНОЛОГИЧЕСКОМ ВУЗЕ./В сборнике: Русский язык и русская культура в мировом культурном пространстве. По материалам Международной научно-практической конференции. Московский государственный университет технологий и управления им. К.Г. Разумовского (Первый казачий университет). 2021. C. 87-92.

(C) Д.А. Ломова, 2021 